\title{
Fertility issue in early stage endometrial cancer patients
}

\author{
Hasan Onur Topçu ${ }^{1}$, Cihan Kaya ${ }^{2}$, Engin Oral $^{3}$ \\ ${ }^{1}$ Department of Obstetrics and Gynecology, Memorial Hospital Ankara, Ankara, Turkey; ${ }^{2}$ Department of Obstetrics and Gynecology, University of \\ Health Sciences Bakirkoy Dr Sadi Konuk Training and Research Hospital, Istanbul, Turkey; ${ }^{3}$ Private Clinic, Obstetrics and Gynecology, Istanbul, \\ Turkey \\ Contributions: (I) Conception and design: All authors; (II) Administrative support: All authors; (III) Provision of study materials or patients: HO \\ Topçu, C Kaya; (IV) Collection and assembly of data: HO Topçu, C Kaya; (V) Data analysis and interpretation: All authors; (VI) Manuscript writing: \\ All authors; (VII) Final approval of manuscript: All authors. \\ Correspondence to: Prof. Engin Oral, MD. Vali Konağı Cad. Saroğlu Apt. No: 83 Kat:3 D: 10 Nişantaşı, Istanbul. Email: drenginoral@gmail.com.
}

\begin{abstract}
Endometrial cancer (EC) is the most common cancer of the female reproductive system in developed countries. The incidence of EC has been increasing in young women. Approximately $4 \%$ of cases are aged $<40$ years. These young women may wish to delay therapy until after they have children. Common complaints in patients with EC include irregular vaginal bleeding, pelvic pain, and enlarged uterus. Imaging techniques such as transvaginal ultrasound (TVUS) or magnetic resonance imaging (MRI) can be utilized in detecting EC. Although the recommended treatment of EC is hysterectomy and bilateral salpingo-oophorectomy with or without systemic lymph node dissection, loss of reproductive function is the primary limiting factor of this surgical approach. Some studies have reported favorable results with high-dose oral progestins or levonorgestrel-releasing intrauterine system or hysteroscopic tumor resection followed by treatment with high-dose oral progestins. The most widely utilized medical treatment regimens are medroxyprogesterone acetate (MPA) 250-600 mg/day or megestrol acetate (MA) 160-480 mg/day. However, there is still a lack of evidence to establish the optimal dose and duration of progestin treatment. Patients with complete remission (CR) who wish to conceive must be encouraged, and referral to a fertility clinic should be offered as soon as possible. The key aspect of fertility-sparing management in women with EC appears to be the selection of appropriate candidates. Owing to the rarity of this condition, management may often be suboptimal. The aim of this review is to assess the current approaches to management of young women with EC who wish to preserve their fertility.
\end{abstract}

Keywords: Endometrial cancer (EC); fertility-sparing; progestins; recurrence

Submitted May 31, 2020. Accepted for publication Jul 31, 2020.

doi: $10.21037 /$ tcr-20-2232

View this article at: http://dx.doi.org/10.21037/tcr-20-2232

\section{Introduction}

Endometrial cancer (EC) is one of the most common gynecological cancers worldwide $(1,2)$. Although EC is more prevalent in postmenopausal women, $7.1 \%$ of patients are diagnosed at ages ranging from 20 to 44 years, and over $70 \%$ of them are nulliparous at the time of diagnosis $(3,4)$. The majority of ECs are diagnosed at an early stage ( $80 \%$ in stage I), with a 5 -year survival rate over $95 \%$. Early detection of EC is possible since most of the patients present with vaginal bleeding $(5,6)$.
EC has been stratified into two main types as Type I and Type II. Type I EC is the endometrioid type related to genetic mutations, obesity, polycystic ovarian syndrome, and hyperestrogenic state (7). On the other hand, Type II ECs have relatively poor prognosis as they are often associated with older age, advanced disease stage, higher tumor grade, non-endometrioid histopathological types such as serous, clear-cell, and undifferentiated carcinomas (8).

Patients with EC commonly have a high body mass index (BMI) associated with the hyperestrogenic state. This could be explained by the peripheral conversion of androgens 
to estrogen in adipose tissue via the aromatase enzyme. Besides, other conditions with the higher estrogenic state, such as nulliparity, estrogen-releasing tumors, early menarche/late menopause, and exposure to unopposed estrogen, also increase the risk of EC $(4,9,10)$. EC is also related to systemic diseases such as hypertension and diabetes mellitus (10).

The incidence of EC has been increasing in women of reproductive age, who are candidates of fertilitysparing management (11). The key aspect of fertilitysparing management in women with EC is the selection of appropriate candidates (11) and optimal treatment as well as follow-up strategies are also crucial. However, management of EC is often suboptimal due to the rarity of this condition.

This review aims to assess the current approaches to management of young women with $\mathrm{EC}$ who wish to preserve their fertility.

\section{Diagnosis}

Common complaints in women with EC include irregular vaginal bleeding, pelvic pain, and enlarged uterus. Imaging techniques such as transvaginal ultrasound (TVUS) or magnetic resonance imaging (MRI) may be utilized in detecting possible endometrial thickness, myometrial invasion, and exclusion of other pelvic pathologies to support the diagnosis.

MRI, which is primarily performed to detect myometrial invasion, may also be useful for revealing synchronous or metastatic adnexal/ovarian tumors and evaluating the ovaries. The incidence of synchronous ovarian malignancies in women with $\mathrm{EC}$ who are $<40$ years of age at the time of diagnosis has been reported as $4.5 \%$ (21 of 471 patients) (12).

According to the current knowledge, MRI seems to be slightly more sensitive than ultrasound to evaluate myometrial invasion and lymph node involvement (13). Contrast-enhanced MRI is reportedly superior for detecting myometrial invasion compared to non-enhanced MRI and TVUS (14). However, MRI is expensive and not readily available in all centers. In a study, TVUS detected myometrial invasion at a rate comparable to that of MRI (15).

Another study investigated the utility of PET-CT scan to detect lymph node metastasis in the preoperative workup of EC (16). The low sensitivity (75\%; 95\% CI, 21.9-98.7) and low positive predictive value $(50 \%$; $95 \%$ CI, $13.9-86.1)$ of PET-CT scan in detecting lymph node metastasis in intermediate-and high-risk early-stage EC were reported as the obstacles to routine use of this tool in the preoperative workup of EC (16).

Reduced relative telomere length (RTL) in circulating cell-free DNA (cfDNA) in serum has emerged as a noninvasive, simple and relatively inexpensive diagnostic tool that is promising in the early detection of EC (17). However, RTL in cfDNA is not specific for EC and it may be influenced by several factors. Large-scale studies are warranted to use cfDNA RTL in differentiating atypical endometrial hyperplasia (AEH) from EC in clinical practice (17).

The presence of glandular cells in the preoperative cervical smear of patients with EC was also evaluated, which was associated with higher local recurrence risk (18). Therefore, presence of glandular cells in the preoperative cervical smear might be considered as a risk factor for recurrence in patients with EC who undergo fertilitysparing treatment (18).

Endometrial biopsy is the first step for the diagnosis of malignant pathologies of the endometrium. Establishing the grade and stage of the tumor is both the most challenging and the most important aspect of fertility-sparing management in women with EC. The diagnosis should be based on adequate endometrial sampling performed via pipelle, dilation and curettage (D\&C), or hysteroscopy (19-21).

\section{Treatment overview}

The recommended treatment of EC is hysterectomy with bilateral salpingo-oophorectomy with or without systemic lymph node dissection, followed by peritoneal washing sampling. After the surgery, some patients may need adjuvant chemotherapy or radiotherapy depending on the tumor size, grade, and definitive pathological diagnosis (4). Although the above mentioned standard radical treatment for EC is a practical approach in most patients, the loss of reproductive function is the primary limiting factor of this treatment modality, mainly in patients of reproductive age who wish to preserve their fertility. For this reason, a conservative approach may be feasible and safe for the initial treatment of EC in selected patients $(1,22)$.

A fertility-sparing strategy may be feasible in patients aged $<40$ years and who strongly wish to preserve fertility. These candidates should be in a 'low-risk category' based on histologically confirmed well-differentiated endometrioid adenocarcinoma, tumor confined to endometrium with a diameter of $<2.0 \mathrm{~cm}$, without extrauterine metastasis and 
myometrial and/or lymphovascular space invasion (LVSI) $(3,4)$.

However, previous studies have reported that patients with stage IA type I and Grade 2 EC may also be candidates for fertility-sparing treatment (11).

Endometrioid and non-endometrioid endometrial tumors are associated with genomic alterations but applying standard genomic evaluation to all women with $\mathrm{EC}$ is not recommended. In a histological evaluation, lower estrogen receptor/progesterone receptor expression levels were observed in EC patients with loss of mismatch proteins, which is why. they could not be considered as appropriate candidates for progesterone therapy (23). On the other hand, patients at risk of hereditary nonpolyposis colorectal cancer/Lynch Syndrome, which is caused by mutations in DNA mismatch repair genes, should be referred to genetic consultation. Conservative treatment should be avoided in the presence of such genetic defects (3).

The primary aim of fertility-sparing treatment is achieving complete remission (CR), which is defined as the absence of disease in the subsequent endometrial biopsy. Partial response is defined as the downgrading of EC to complex atypical endometrial hyperplasia $(\mathrm{AEH})$. The patients without response are those with no improvement in terms of histopathology, whereas disease progression is defined as the presence of a higher grade of cancer in the final pathology result (4).

\section{Fertility-sparing treatments}

\section{Medical treatment}

\section{Progestins}

Up to now, medical treatment has been widely recommended to patients with $\mathrm{EC}$ who are willing to preserve their fertility. For that purpose, the earlier trials of conservative management were based on oral progestin treatment (24). Two types of oral progestins, namely medroxyprogesterone acetate (MPA) and megestrol acetate (MA), have been used with reported complete remission rates varying from $62 \%$ to $90.7 \%(4,24-28)$.

To evaluate the efficacy and safety of oral progestin treatment in patients with early-stage EC, Qin et al. performed a meta-analysis covering a total of 445 patients from 25 articles. The progestins used in these studies were MPA (16/25) and MA (16/25), at doses of 10-1,500 and $40-400 \mathrm{mg} /$ day, respectively. The patients had a CR rate of $82.4 \%$, a recurrence rate (RR) of $25.0 \%$, a pregnancy rate
(PR) of $28.8 \%$, and a live birth rate (LBR) of $19.6 \%$. Only two deaths were reported during the follow-up period (25).

In another study, Yamagami et al. reported patients with EC who received fertility-preserving treatment. One hundred and sixty-two of these patients $\mathrm{m}$ received initial treatment with MPA, and 82 of them received repeated MPA treatment due to recurrent disease. Oral MPA administration varied between doses of 400 to $600 \mathrm{mg} /$ day until pathologically confirmed tumor disappearance. CR rate was $90.7 \%$ in the initial treatment group, and $98.1 \%$ in the repeated treatment group. The 5-year recurrencefree survival (RFS) rate was $33.2 \%$ for the initial treatment group, and $11.2 \%$ for the recurrent treatment group. The study reported encouraging results for patients with EC recurrence after initial hormonal therapy (26).

Greenwald et al. performed a large-scale propensity score-matched study and compared the mortality outcomes of patients who had hormonal treatment and those who received surgical treatment due to early-stage EC. The study comprised of 6,339 patients, 161 of whom received progestins such as medroxyprogesterone (MP), MPA and MA and 6,178 patients who underwent primary surgery. After an average follow-up of 15 years, the mortality rate did not differ between the progestin group and the primary surgery group ( $14.1 \%$ vs. $9.3 \%$, respectively) (29).

According to the current literature, the most commonly used regimens are MPA $250-600 \mathrm{mg} /$ day or MA 160 $480 \mathrm{mg} /$ day $(30,31)$. However, there is still a lack of evidence to establish the optimal dose and duration of progestin treatment. The variations in treatment regimens may be explained by age, obesity, tumor grade, and the absence or presence of progesterone receptors $(1,4)$.

\section{Levonorgestrel-releasing intrauterine device}

Apart from oral therapy, progesterone treatment may also be administered using a temporary levonorgestrel-releasing intrauterine device (LNG-IUD) (32). In terms of avoiding the systemic adverse effects of high-dose oral progestins, LNG-IUDs, which release an initial dose of $20 \mathrm{mcg} / \mathrm{day}$ progestin locally are considered to have less systemic side effects than oral preparations (32).

In a systemic analysis of 189 patients diagnosed with $\mathrm{AEH}$, a precursor of EC, Chen et al. reported that LNGIUD treatment provided a higher regression rate than oral progestogens (90\% vs. 69\%, respectively) (33). In another retrospective study by Pal et al. (7-24), LNGIUD treatment was associated with a success rate of $80 \%$ at six months in $\mathrm{AEH}$ patients $(\mathrm{n}=15), 67 \%$ in grade $1 \mathrm{EC}$ 
$(\mathrm{n}=9)$ patients and of $75 \%$ in grade $2 \mathrm{EC}(\mathrm{n}=8)$. The use of LNG-IUD as the first-line treatment for AEH has is also recommended in the Royal College of Obstetrics and Gynaecology guideline (24-33).

As will be seen in the next sections, LNG-IUD is mostly used for maintenance therapy after hysteroscopic resection (HR) in early-stage EC patients who opt for fertilitysparing treatment.

\section{Combined therapies}

The idea of using combination strategies rather than progestin treatment alone emerged to achieve better results and reduce the side effects of oral hormonal therapies. Qin et al. evaluated the side effects of long-term MPA and MA treatment, and concluded that weight gain, liver dysfunction, and abnormal blood coagulation tests were the most common side effects that restrict young women's compliance to treatment. For this reason, LNG-IUD, $\mathrm{GnRH}$ agonist (GnRHa), and aromatase inhibitors (AIs) have been used as adjuvant medications $(32,34)$.

In a study by Chae et al., 118 patients with EC received combined therapy with concurrent oral MPA treatment and LNG-IUD. Seventy-one $(60.17 \%)$ patients achieved $\mathrm{CR}$, and the median duration of hormonal therapy was 11.9 months (range, 4-49) (35). Kim et al. conducted a prospective phase II study in 44 patients with grade $1 \mathrm{EC}$. They treated the patients with a combination of oral MPA (500 mg/day) and LNG-IUD. After six months of followup, 35 patients had completed the study protocol and the CR rate at six months was $37.1 \%$ (13/35). Partial response was reported as $25.7 \%(9 / 35)$, and none of the patients had progressive disease (36).

In regard to the idea of metformin, which increases the expression of the progesterone receptor and sensitizes progestin-resistant EC cells to progestin-induced apoptosis $(37,38)$, Yang et al. conducted a study in 150 patients diagnosed with AEH or well-differentiated EC. The study population was randomized into two groups. The first group comprised of patients receiving oral MA $160 \mathrm{mg} /$ day $(\mathrm{n}=74)$ and the second group received oral MA $160 \mathrm{mg} / \mathrm{day}+$ oral metformin $500 \mathrm{mg}$ three times a day $(\mathrm{n}=76)$. They observed a higher CR rate in EC patients in the MA+metformin group compared to the MA-only group at 16 weeks of follow-up (34.3\% vs. $20.7 \%$, respectively). The CR rate was significantly higher in AEH patients after treatment (39.6\% vs. $20.4 \%$ ). As a fertility-sparing treatment, MA+metformin treatment seems to be a promising option in terms of a higher CR rate than MA alone in both patients with $\mathrm{AEH}$ and EC (37).

The other combined treatment options are GnRHa and AIs (39-42). GnRHa, which acts by downregulating gonadotropins, has been used to treat EC in patients who wish to preserve their fertility (39). GnRHa is commonly used in combination with other medications such as progestins and AIs. AIs act by inhibiting the peripheral conversion of androgens in adipose tissue, thereby reducing estrogen levels. The use of AIs is considered to be beneficial, especially in EC patients with higher BMI (40).

In a study involving 29 patients diagnosed with EC or AEH, 18 patients received combination therapy with intramuscular injections of GnRHa every four weeks and an LNG-IUD (Mirena ${ }^{\circledR}$ Bayer Health Care Pharmaceutical Inc, Wayne, NY, USA) was inserted. Eleven patients were treated with the combination of intramuscular GnRHa injections every four weeks in addition to oral letrozole $2.5 \mathrm{mg}$ daily. They reported that $88.2 \%(15 / 17)$ of the patients with EC had CR, and only one of them had EC recurrence (32).

Thangavelu et al. reported a randomized pilot study in 16 women with EC treated with $\mathrm{AI}$ (anastrozole arm) versus placebo 14 days before definitive surgery. They concluded that a significant decrease was observed in the glandular expression of estrogen and androgen receptors, and ki-67, a proliferation marker, in the anastrozole arm compared to placebo (40).

In another study, six obese EC patients receiving either intramuscular injections of GnRHa $3.75 \mathrm{mg}$ every four weeks or oral AI $2.5 \mathrm{mg} /$ day were evaluated. According to the study results, the CR rate was $100 \%$ and time to CR was 3-6 months with no recurrence after a median follow-up of 4 years. The most commonly reported side effects were menopause-like symptoms. The PR and LBR was 50.0\% and $75.0 \%$, respectively (41).

\section{Fertility-sparing surgical treatment}

Although there are promising results with medical treatment in EC patients, the absence of a standard treatment regimen and the aim of achieving fewer RRs have led to the necessity of new treatment approaches (3). Recently, in addition to better disease-free outcomes, improved PR has been reported in EC survivors after fertility-sparing combined therapy consisting of HR and hormonal treatment $(43,44)$.

HR is useful in the treatment of grade I EC patients, and also effective in patients with highly differentiated EC willing to retain fertility (3). HR for the treatment of EC involves resection of the tumor with a small layer of the 
myometrium immediately beneath the lesion (two-step technique) and resection of the endometrium adjacent to cancer in addition to the two-step technique (three-step technique) (3).

To evaluate the efficacy of hysteroscopic evaluation and lesion resection combined with progestin therapy, Yang et al. retrospectively reported a total of 120 patients, 80 of whom were diagnosed with AEH and 40 had early-stage EC. All patients received oral progestin until achieving CR after HR, and 148 (97.4\%) patients achieved CR while 3 patients with $\mathrm{AEH}$ and 1 with EC had disease progression. The mean treatment duration to achieve CR was $6.7 \pm 0.3$ months (range, $1-18$ months). After achieving CR, 60 patients attempted to conceive. They reported 45.0\% (15/60) PR and 25.0\% (15/60) LBR, while 6.7\% experienced spontaneous abortion (45).

Falcone et al. reported their 15-year experience of fertility-sparing treatment in patients with early EC who underwent HR and received progestin therapy with MA or LNG-IUD for at least six months. At the 3rd month of progestin therapy, 25 (89.3\%) patients had CR, two $(7.1 \%)$ had persistent disease, whereas one $(3.6 \%)$ patient presented with progressive disease and required definitive surgery. At 6 months, only one patient underwent definitive surgery, while the others had CR. The median duration of CR was 94.5 months (range, 8-175 months) for the study population. Of the patients with CR, $57.7 \%$ attempted to conceive, and $93.3 \%$ PR and $86.6 \%$ LBR (44).

A meta-analysis by Zhang et al., which included fiftyfour studies evaluating fertility-sparing therapies in young women with EC and AEH showed that HR followed by progestins achieved a significantly higher pooled regression (98.06\% vs. $77.20 \%)$ and LBR $(52.57 \%$ vs. $33.38 \%)$ and a lower RR compared to oral progestins alone $(4.79 \% v s$. $32.17 \%)$. Furthermore, pooled LBR (52.57\% vs. 18.09\%) with HR followed by progestins was significantly higher than that with LNG-IUD alone. However, no statistical difference was observed in RR (4.79\% vs. 3.90\%) (46).

Tock et al. reported 18 women with grade $1 \mathrm{EC}$ or endometrial intraepithelial neoplasia (EIN). All patients received GnRHa treatment for three months after HR. The patients underwent follow-up at 3-month intervals. After a median follow-up of 40.7 months, CR was observed in 12 patients $(66.7 \%)$, however 3 of them later had recurrence (25\%) (47).

Overall, combination treatment with medical therapy and HR seems to reduce RR with higher LBR compared to that of hormonal therapy alone.

\section{Follow-up}

The first year of post-treatment follow-up should include serial TVUS examinations, a diagnostic hysteroscopy, and endometrial sampling with three-month intervals (48). Patients with a partial response following six months of treatment may be offered continuation of treatment for another 3 to 6 months. It has been reported that $80 \%$ of patients show complete remission after 12 months. Therefore, women who do not achieve complete remission by 12 months may be considered non-responders and should be recommended surgery (49). Patients with CR who wish to conceive should be encouraged, and referral to a fertility clinic should be offered as soon as possible, especially if they have increased risk for EC such as obesity, thick endometrium, older age, and history of recurrence (50).

\section{Prognostic factors of treatment response}

In regard to the different response rates of different treatment modalities in patients with EC who wish to preserve their fertility, some prognostic factors have been predicted. For that purpose, Koskas et al. conducted a systematic review including 370 patients from 24 studies and reported that factors such as age, gravidity status, obesity, history of infertility, or hormonal therapy were not associated with an increased risk of recurrence (51). Moreover, pregnancy was associated with a lower EC RR compared to that in patients who did not conceive. Park et al. reported a $20.5 \%(9 / 44) \mathrm{RR}$ for EC in the patients those who conceived and $36.6 \%(26 / 71)$ in the nonpregnant group. Multivariate analysis also showed a significant association between RFS (OR 0.25; 95\% CI, 0.11 to $0.56 ; \mathrm{P}=0.001$ ) and pregnancy $(52)$. The study by Chae $e t$ al. also observed that EC recurrence was lower in the conceived group than in the non-pregnant group, and the time to recurrence was significantly higher in the pregnant group than that in the non-pregnant group. These results may be due to prolonged exposure to endogenous progesterone during pregnancy, which affects the endometrial proliferation (35). However, in another retrospective study by Chen et al., they found a relation between EC recurrence and older age ( $\geq 35$ years), obesity (body mass index $\geq 30 \mathrm{~kg} / \mathrm{m}^{2}$ ), time to achieving CR, and infertility after conservative treatment (53).

Yin et al. evaluated the variables that may be related to EC recurrence in 127 patients. Fifty-three patients were in the recurrence group and 74 were in the control group. After adjusting the model for interfering factors, 
menstruation cycle, progestin type, and regular maintenance treatment after CR were defined as the main risk factors of recurrence (54).

Travaglino et al. conducted a review to assess the predictive role of phosphatase and tensin homolog (PTEN) expression in 376 patients treated with progestin due to EC and AEH. The study concluded that PTEN loss was not significantly associated with the outcome of therapy in the overall analysis (55).

According to the results of the studies mentioned above, older age ( $\geq 35$ years), obesity (body mass index $\geq 30 \mathrm{~kg} / \mathrm{m}^{2}$ ), and infertility after conservative treatment seem to be related to recurrence due to the high exposure to estrogen. However, there is a lack of evidence to confirm these associations.

\section{Treatment after recurrence}

The primary concern with fertility-sparing treatment is the recurrence and progression of EC and related mortality. The reported RR following CR varies from $24 \%$ to $40 \%$ in $4-66$ months $(23,56)$. However, the mortality rate associated with conservative treatment of early-stage EC is still quite low (57).

Wang et al. reported their 15-year experience of prolonged conservative treatment in patients with recurrent EC. The study included 41 patients with recurrent EC with a median disease-free period of 16 months (range, 5-55 months). Twenty-three of the patients were diagnosed with recurrence as EC, and 18 of them had AEH or EIN. Twenty-six patients received repeated conservative treatment. The CR rate for these patients was $82.6 \%$, which was lower than the $94.7 \%$ CR rate of initial fertilitypreserving treatment. The CR rate of AEH/EIN patients was higher than that of EC patients, with $92.9 \%$ vs. $66.7 \%$. Among the patients who achieved CR, 19 tried to conceive, and 3 conceived and delivered successfully. Four cases required definitive surgery due to the failed response to repeated treatment (58).

There is only limited data and no adopted strategy regarding the optimal management of patients with early-stage EC recurrence after conservative treatment (26,59-61). A recent study recommended that the total duration of treatment may be extended to 3-36 months in case of recurrent disease $(62,63)$. The European Society for Gynecological Oncology guidelines indicate that high-dose progestin therapy can be re-administered in patients with disease recurrence after CR. Still, this recommendation should be preserved only for nulliparous women (64).

After completion of fertility, hysterectomy and salpingooophorectomy should be recommended (65). The preservation of ovaries may be considered taking into account the patient's age and genetic risk factors, and this option should be discussed with the patient.

For patients with recurrent EC after primary conservative treatment, repeated fertility-preserving treatment can still provide a promising response, and patients have possibilities of completing childbirth.

\section{Management after completion of conservative treatment}

\section{Women who wish to conceive}

Following fertility-sparing treatment, reproductive management should be planned as soon as possible. Patients with CR and no history of infertility may try natural conception, although the PR is expected to be low because of the thin endometrium. To tackle this problem, assisted reproductive technologies (ARTs) should be considered to increase the chance of fertility (66-68). The reported PR in the literature after hormonal treatment is between $35-80 \%$ and LBR ranges from $40.9 \%$ to $80 \%(3,4,69-71)$ (Figure 1 ).

Kim et al. reported 22 patients who underwent IVF cycles after progestin treatment for stage IA EC. The mean age of the study group was 34 years (range, 26-41 years). Fortynine embryo transfers were performed after two months of last progestin treatment. Clinical PR per transfer was $26.5 \%$, implantation rate was $16.7 \%$, and LBR was $14.3 \%$. The cumulative clinical PR was 50\% (11/22), resulting in 6 live births $(27.3 \%)$ within three cycles of embryo transfer. This study showed an acceptable cumulative PR after the IVF procedure in patients with early-stage EC who were treated conservatively (72).

In a multicenter study evaluating pregnancy outcomes of progestin therapy, $33.3 \%$ (9/27) of the patients conceived, and $18.5 \%(5 / 27)$ of them delivered successfully after conservative treatment. The mean time to pregnancy was 12.2 months (range, 4-25 months). The reported PR varied from $12.5 \%$ to $50 \%$, and delivery rates were between $9.1 \%$ to $30 \%(66,73,74)$.

There are only limited data about the factors associated with PR after conservative hormonal treatment in patients with early EC $(23,32)$. Inoue $e$ al . reported factors affecting PR in 98 patients who received MPA treatment for welldifferentiated EC or AEH. They concluded that recurrence 


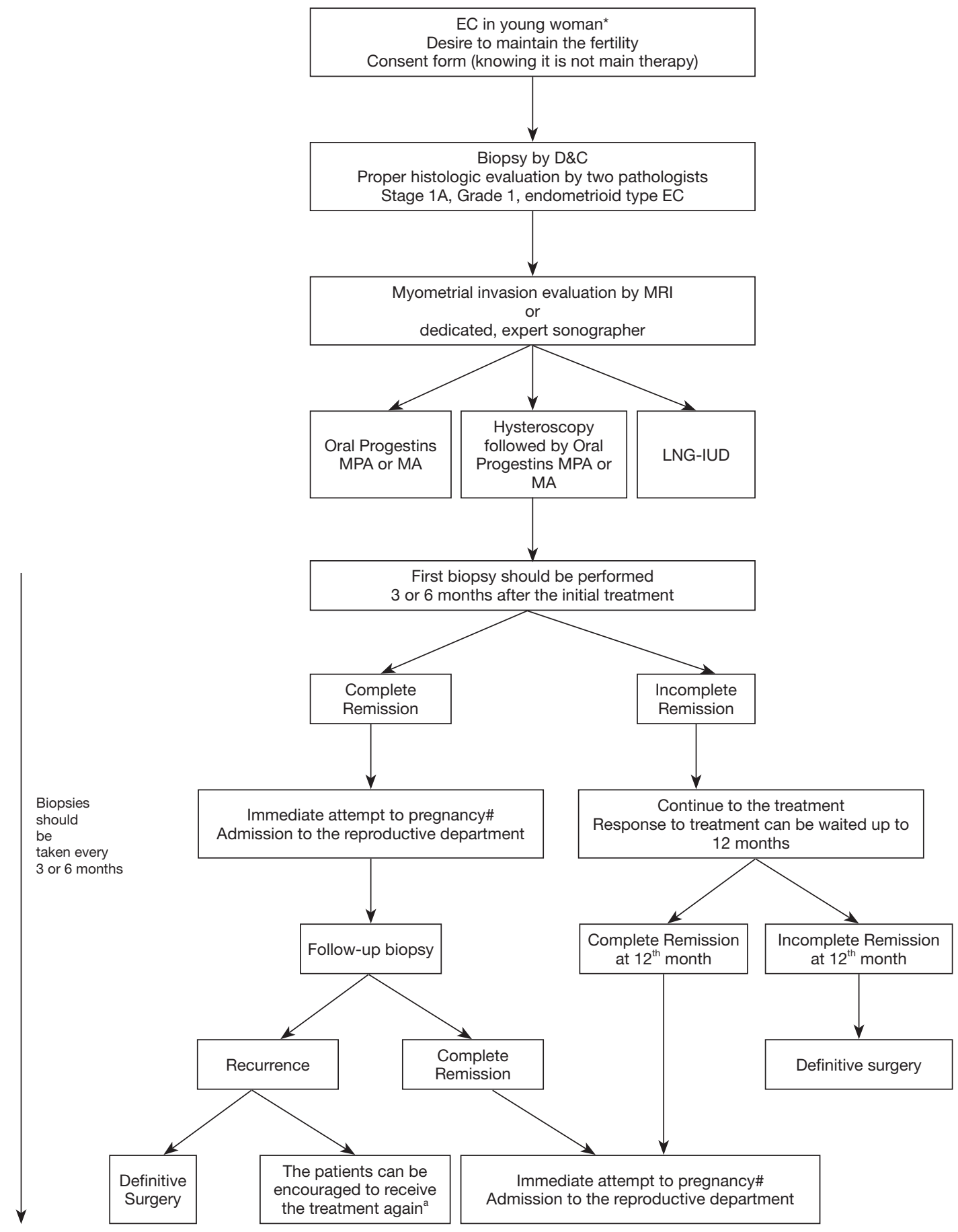

*, there is no cut-off value for age; the ovarian reserve should be tested in selected cases; \#, The maximum time to wait for conception is unclear. a, high complete remission rates were reported after recurrence (55). D\&C, Dilatation and curettage, MRI: magnetic resonance imaging, MPA: medroxyprogesterone acetate, MA, megestrol acetate, LNG-IUD: levonorgestrel releasing intrauterine system. EC,

endometrial cancer.

Figure 1 Algorithm of the fertility-sparing management in women with early stage endometrial cancer patients. 
before conception, endometrial thickness during ovulation, and the patient's age were associated with lower PR (75).

It has been suggested that tumor grade is the only factor related to a successful pregnancy. Tumor grade and PR are thought to be associated due to the increased level of plasminogen activator inhibitor type 1 , which is observed in grade 2/3 EC (76,77). Plasminogen activator inhibitor inhibits the fibrinolytic system and acts in thrombus formation associated with implantation failure. To elucidate a major concern of fertility-preserving surgery, the relationship between recurrence and pregnancy, Yin et al. reported that the rate of successful pregnancy was $62.5 \%$ in patients who achieved CR with initial treatment, and 20.5\% in the recurrence group after CR of the primary disease (54).

Another problem with fertility-preserving treatment is the repetition of $\mathrm{D} \& \mathrm{C}$ and hysteroscopies that may adversely impact embryo implantation due to destruction of the basal layer of the endometrium, intrauterine adhesions, and fibrosis (78). However, Chae et al. reported no significant difference between the pregnant group (4, range 2-7) and the non-pregnant group (4, range 2-7) considering the number of D\&Cs. Although there is insufficient data, utilization of anti-adhesive materials after D\&C may prevent adhesion formation by recovering the basal layer of the endometrium in the early healing phase (35).

Another study reported that no intrauterine adhesions were observed after HR, and these cases had high PR and LBR. These findings suggest that HR may have no significant adverse effects on pregnancy outcomes (3).

Secondary effects of fertility-preserving treatment are associated with obstetrical outcomes. ART seems not to affect the prognosis of EC $(29,79)$. However, perinatal complications, including preterm birth, preeclampsia, multiple pregnancies, and the need for the cesarean section should be considered in patients who underwent ART (80).

\section{Women without pregnancy desire}

The patients who achieve CR and do not wish to preserve fertility should be recommended administration of oral low-dose progesterone considering the clinical practice guidelines issued by the European Society for Medical Oncology (30). However, there is still a lack of evidence on a specific dose regimen and administration period. LNGIUDs may be considered as an alternative treatment to oral hormonal medications.

Sexual functioning and psychological well-being of women

\section{affected by EC}

In a cross-sectional study, 470 cervical and ovarian cancer survivors between the ages of 18-40 years were evaluated. No differences were observed between the fertilitysparing group and the definitive surgery group regarding sexual functioning and quality of life scores (81). There is a lack of adequate data about the quality of life and sexual functioning in patients with $\mathrm{EC}$ who wish to preserve their fertility (82). Although these patients undergo hysteroscopy and biopsy procedures, without any surgical procedures that may impair their sexual functioning, a cancer diagnosis itself, and certain non-surgical treatments may cause sexual problems, depression, anxiety, and loss of self-esteem $(83,84)$.

\section{Conclusions}

In younger patients with stage IA EC who are willing to become pregnant, fertility-preserving treatment appears to be feasible and useful, however, relevant evidence remains limited. Adequate evaluation and an accurate diagnosis are mandatory to predict the appropriate candidates for this treatment modality. There are various treatment options such as oral progestin therapy, LNG-IUDs, HR, GnRHa therapy, and AIs alone or in combination. Combination treatments with HR following medical therapy may improve the RR. However, further research is needed to confirm their effectiveness, the optimal dosage, route of administration, and duration of treatment. After achieving $\mathrm{CR}$, women who wish to conceive should be encouraged to attempt conception as soon as possible. ARTs may offer a shorter time to conception compared to spontaneous conception. Regular oncology follow-up should be offered with intervals of 6 months. Individualization of the treatment is crucial as each patient has different characteristics such as age, BMI, tumor grade, and treatment response.

\section{Acknowledgments}

Funding: None.

\section{Footnote}

Provenance and Peer Review: This article was commissioned by the Guest Editor (Antonio Simone Laganà) for the series "Endometrial Cancer" published in Translational Cancer 
Research. The article was sent for external peer review organized by the Guest Editor and the editorial office.

Conflicts of Interest: All authors have completed the ICMJE uniform disclosure form (available at http://dx.doi. org/10.21037/tcr-20-2232). The series "Endometrial Cancer" was commissioned by the editorial office without any funding or sponsorship. The authors have no other conflicts of interest to declare.

Ethical Statement: The authors are accountable for all aspects of the work in ensuring that questions related to the accuracy or integrity of any part of the work are appropriately investigated and resolved.

Open Access Statement: This is an Open Access article distributed in accordance with the Creative Commons Attribution-NonCommercial-NoDerivs 4.0 International License (CC BY-NC-ND 4.0), which permits the noncommercial replication and distribution of the article with the strict proviso that no changes or edits are made and the original work is properly cited (including links to both the formal publication through the relevant DOI and the license). See: https://creativecommons.org/licenses/by-nc-nd/4.0/.

\section{References}

1. Carneiro MM, Lamaita RM, Ferreira MC, et al. Fertility preservation in endometrial cancer: is it safe? Review of the literature. JBRA Assist Reprod 2016;20:232-9.

2. Qian JM, Stahl JM, Young MR, et al. Impact of vaginal cylinder diameter on outcomes following brachytherapy for early stage endometrial cancer. J Gynecol Oncol 2017;28:e84.

3. Wang Y, Yang JX. Fertility-preserving treatment in women with early endometrial cancer: the Chinese experience. Cancer Manag Res 2018;10:6803-13.

4. Trojano G, Olivieri C, Tinelli R, et al. Conservative treatment in early stage endometrial cancer: a review. Acta Biomed 2019;90:405-10.

5. Siegel R, Ma J, Zou Z, et al. Cancer statistics, 2014. CA Cancer J Clin 2014;64:9-29.

6. Lee NK, Cheung MK, Shin JY, et al. Prognostic factors for uterine cancer in reproductive-aged women. Obstet Gynecol 2007;109:655-62.

7. Cicchillitti L, Corrado G, Carosi M, et al. Lamin A as novel molecular prognostic biomarker for EC. It J Gynaecol Obstet 2016;28:N2.
8. Bogani G, Dowdy SC, Cliby WA, et al Management of endometrial cancer: issues and controversies. Eur J Gynaecol Oncol 2016;37:6-12.

9. Lasalandra C, Coviello M, Falco G, et al. Serum Vascular Endothelial Growth Factor and Adiponectin Levels in Patients with Benign and Malignant Gynecological Disease. Int J Gynecol Cancer 2010;20:507-12.

10. Corzo C, Santillan NB, Shannon N. Westin, Ramirez P, Updates on Conservative Management of Endometrial Cancer. J Minim Invasive Gynecol 2018;25:308-13.

11. Vitale SG, Rossetti D, Tropea A, et al. Fertility sparing surgery for stage IA type I and G2 endometrial cancer in reproductive-aged patients: evidence-based approach and future perspectives. Updates Surg 2017;69:29-34.

12. Song T, Seong SJ, Bae DS, et al. Synchronous primary cancers of the endometrium and ovary in young women: a Korean Gynecologic Oncology Group Study. Gynecol Oncol 2013;131:624-8.

13. Frei KA, Kinkel K, Bonél HM, et al. Prediction of deep myometrial invasion in patients with EC: clinical utility of contrast-enhanced MR imaging-a meta-analysis and Bayesian analysis. Radiology 2000;216:444-9.

14. Kinkel K, Kaji Y, Yu KK, et al. Radiologic staging in patients with endometrial cancer: a meta-analysis. Radiology 1999;212:711-8.

15. Savelli L, Ceccarini M, Ludovisi M, et al. Preoperative local staging of endometrial cancer: transvaginal sonography vs. magnetic resonance imaging. Ultrasound Obstet Gynecol 2008;31:560-6.

16. Franchi M, Garzon S, Zorzato PC, et al. PET-CT scan in the preoperative workup of early stage intermediate- and high-risk endometrial cancer. Minim Invasive Ther Allied Technol 2020;29:232-9.

17. Benati M, Montagnana M, Danese E, et al. Aberrant Telomere Length in Circulating Cell-Free DNA as Possible Blood Biomarker with High Diagnostic Performance in Endometrial Cancer. Pathol Oncol Res 2020;26:2281-9.

18. Casarin J, Bogani G, Serati M, et al. Presence of Glandular Cells at the Preoperative Cervical Cytology and Local Recurrence in Endometrial Cancer. Int J Gynecol Pathol 2020;39:522-8.

19. Stovall TG, Photopulos GJ, Poston WM, et al. Pipelle endometrial sampling in patients with known endometrial carcinoma. Obstet Gynecol 1991;77:954-6.

20. Dijkhuizen FP, Mol BW, Brolmann HA, et al. The accuracy of endometrial sampling in the diagnosis of patients with endometrial carcinoma and hyperplasia: a 
meta-analysis. Cancer 2000;89:1765-72.

21. Trojano G, Damiani GR, Casavola VC, et al. The Role of Hysteroscopy in Evaluating Postmenopausal Asymptomatic Women with Thickened Endometrium. Gynecol Minim Invasive Ther 2018;7:6-9.

22. Wright JD, Buck AM, Shah M, et al. Safety of ovarian preservation in premenopausal women with endometrial cancer. J Clin Oncol 2009;27:1214-9.

23. Garg K, Shih K, Barakat R, et al. Endometrial carcinomas in women aged 40 years and younger: tumors associated with loss of DNA mismatch repair proteins comprise a distinct clinicopathologic subset. Am J Surg Pathol 2009;33:1869-77.

24. Pal N, Broaddus RR, Urbauer DL, et al. Treatment of Low-Risk Endometrial Cancer and Complex Atypical Hyperplasia With the Levonorgestrel-Releasing Intrauterine Device. Obstet Gynecol 2018;131:109-16.

25. Qin Y, Yu Z, Yang J, et al. Oral Progestin Treatment for Early-Stage Endometrial Cancer: A Systematic Review and Meta-analysis. Int J Gynecol Cancer 2016;26:1081-91.

26. Yamagami W, Susumu N, Makabe T, et al. Is repeated high-dose medroxyprogesterone acetate (MPA) therapy permissible for patients with early stage endometrial cancer or atypical endometrial hyperplasia who desire preserving fertility? J Gynecol Oncol 2018;29:e21.

27. Topcu HO, Oskovi ZA, Meydanlı MM. Fertility preservation in patients with endometrial cancer. EMJ Repro Health 2015;1:81-6.

28. Dursun P, Erkanli S, Güzel AB, et al. A Turkish Gynecologic Oncology Group study of fertility-sparing treatment for early-stage endometrial cancer. Int J Gynaecol Obstet 2012;119:270-3.

29. Greenwald ZR, Huang LN, Wissing MD, et al. Does hormonal therapy for fertility preservation affect the survival of young women with early-stage endometrial cancer? Cancer 2017;123:1545-54.

30. Colombo N, Creutzberg C, Amant F, et al. ESMOESGO-ESTRO Consensus Conference on Endometrial Cancer: diagnosis, treatment and follow-up. Ann Oncol 2016;27:16-41.

31. Gallos ID, Yap J, Rajkhowa M, et al. Regression, relapse, and live birth rates with fertility-sparing therapy for endometrial cancer and atypical complex endometrial hyperplasia: a systematic review and metaanalysis. Am J Obstet Gynecol 2012;207:266.e1-12.

32. Zhou H, Cao D, Yang J, et al. Gonadotropin-releasing hormone agonist combined with a levonorgestrel-releasing intrauterine system or letrozole for fertility-preserving treatment of endometrial carcinoma and complex atypical hyperplasia in young women. Int J Gynecol Cancer 2017;27:1178-82.

33. Chen $X$. The current situation of the levonorgestrel intrauterine system (LNG-IUS) in conservative treatment for patients with early-stage endometrial cancer and atypical hyperplasia. J Gynecol Oncol 2019;30:e79.

34. Kim MK, Yoon BS, Park H, et al. Conservative treatment with medroxyprogesterone acetate plus levonorgestrel intrauterine system for earlystage endometrial cancer in young women: pilot study. Int J Gynecol Cancer 2011;21:673-7.

35. Chae SH, Shim SH, Lee SJ, et al. Pregnancy and oncologic outcomes after fertility-sparing management for early stage endometrioid endometrial cancer. Int J Gynecol Cancer 2019;29:77-85.

36. Kim MK, Seong SJ, Kang SB, et al. Six months response rate of combined oral medroxyprogesterone/ levonorgestrel-intrauterine system for early-stage endometrial cancer in young women: a Korean Gynecologic-Oncology Group Study. J Gynecol Oncol 2019;30:e47.

37. Yang BY, Gulinazi Y, Du Y, et al. Metformin plus megestrol acetate compared with MA alone as fertilitysparing treatment in patients with atypical endometrial hyperplasia and well-differentiated endometrial cancer: a randomised controlled trial. BJOG 2020;127:848-57.

38. Zhang Z, Dong L, Sui L, et al. Metformin reverses progestin resistance in endometrial cancer cells by downregulating GloI expression. Int J Gynecol Cancer 2011;21:213-21.

39. Asbury RF, Brunetto VL, Lee RB, et al. Goserelin acetate as treatment for recurrent endometrial carcinoma: a Gynecologic Oncology Group study. Am J Clin Oncol 2002;25:557-60.

40. Thangavelu A, Hewitt MJ, Quinton ND, et al. Neoadjuvant treatment of endometrial cancer using anastrozole: a randomised pilot study. Gynecol Oncol 2013;131:613-8.

41. Zhang Z, Huang H, Feng F, et al. A pilot study of gonadotropin-releasing hormone agonist combined with aromatase inhibitor as fertility-sparing treatment in obese patients with endometrial cancer. J Gynecol Oncol 2019;30:e61.

42. Straubhar A, Soisson AP, Dodson M, et al. Successful treatment of low-grade endometrial cancer in premenopausal women with an aromatase inhibitor after failure with oral or intrauterine progesterone. Gynecol 
Oncol Rep 2017;21:10-2.

43. Mazzon I, Corrado G, Masciullo V, et al. Conservative surgical management of stage 1A endometrial carcinoma for fertility preservation. Fertil Steril 2010;93:1286-9.

44. Falcone F Laurelli G, Losito S, et al. Fertility preserving treatment with hysteroscopic resection followed by progestin therapy in young women with early endometrial cancer. J Gynecol Oncol 2017;28:e2.

45. Yang B, Xu Y, Zhu Q, et al. Treatment efficiency of comprehensive hysteroscopic evaluation and lesion resection combined with progestin therapy in young women with endometrial atypical hyperplasia and endometrial cancer. Gynecol Oncol 2019;153:55-62.

46. Zhang Q, Qi G, Kanis MJ, et al. Comparison among fertility-sparing therapies for well differentiated early-stage endometrial carcinoma and complex atypical hyperplasia. Oncotarget 2017;8:57642-53.

47. Tock S, Jadoul P, Squifflet JL, et al. Fertility Sparing Treatment in Patients With Early Stage Endometrial Cancer, Using a Combination of Surgery and GnRH Agonist: A Monocentric Retrospective Study and Review of the Literature. Front Med (Lausanne) 2018;5:240.

48. Pronin SM, Novikova OV, Andreeva JY, et al. FertilitySparing Treatment of Early Endometrial Cancer and Complex Atypical Hyperplasia in Young Women of Childbearing Potential. Int J Gynecol Cancer 2015;25:1010-4.

49. Simpson AN, Feigenberg T, Clarke BA, et al. Fertility sparing treatment of complex atypical hyperplasia and low grade endometrial cancer using oral progestin. Gynecol Oncol 2014;133:229-33.

50. Gadducci A, Spirito N, Baroni E, et al. The fertilitysparing treatment in patients with endometrial atypical hyperplasia and early endometrial cancer: a debated therapeutic option. Gynecol Endocrinol 2009;25:683-91.

51. Koskas M, Uzan J, Luton D, et al. Prognostic factors of oncologic and reproductive outcomes in fertility-sparing management of endometrial atypical hyperplasia and adenocarcinoma: systematic review and meta-analysis. Fertil Steril 2014;101:785-94.

52. Park H, Seok JM, Yoon BS, et al. Effectiveness of highdose progestin and long-term outcomes in young women with earlystage, well-differentiated endometrioid adenocarcinoma of uterine endometrium. Arch Gynecol Obstet 2012;285:473-8.

53. Chen M, Jin Y, Li Y, et al. Oncologic and reproductive outcomes after fertility-sparing management with oral progestin for women with complex endometrial hyperplasia and endometrial cancer. Int J Gynaecol Obstet 2016;132:34-8.

54. Yin J, Ma S, Shan Y, et al. Risk Factors for Recurrence in Patients with Atypical Endometrial Hyperplasia and Endometrioid Adenocarcinoma after Fertility-Sparing Treatments. Cancer Prev Res (Phila) 2020;13:403-10.

55. Travaglino A, Raffone A, Saccone G, et al. PTEN as a predictive marker of response to conservative treatment in endometrial hyperplasia and early endometrial cancer. A systematic review and meta-analysis. Eur J Obstet Gynecol Reprod Biol 2018;231:104-10.

56. Park JY, Kim DY, Kim JH, et al. Long-term oncologic outcomes after fertility-sparing management using oral progestin for young women with EC (KGOG 2002). Eur J Cancer 2013;49:868-74.

57. Ohyagi-Hara C, Sawada K, Aki I, et al. Efficacies and pregnant outcomes of fertility-sparing treatment with medroxyprogesterone acetate for endometrioid adenocarcinoma and complex atypical hyperplasia: our experience and a review of the literature. Arch Gynecol Obstet 2015;291:151-7.

58. Wang Y, Yu M, Yang JX, et al. Prolonged conservative treatment in patients with recurrent endometrial cancer after primary fertility-sparing therapy: 15-year experience. Int J Clin Oncol 2019;24:712-20.

59. Perri T, Korach J, Gotlieb WH, et al. Prolonged conservative treatment of endometrial cancer patients: more than 1 pregnancy can be achieved. Int J Gynecol Cancer 2011;21:72-8.

60. Park JY, Lee SH, Seong SJ, et al. Progestin re-treatment in patients with recurrent endometrial adenocarcinoma after successful fertilitysparing management using progestin. Gynecol Oncol 2013;129:7-11.

61. Tamauchi S, Kajiyama H, Utsumi F, et al. Efficacy of medroxyprogesterone acetate treatment and retreatment for atypical endometrial hyperplasia and endometrial cancer. J Obstet Gynaecol Res 2018;44:151-6.

62. Tangjitgamol S, Manusirivithaya S, Hanprasertpong J. Fertility-sparing in endometrial cancer. Gynecol Obstet Invest 2009;67:250-68.

63. Erkanli S, Ayhan A. Fertility-sparing therapy in young women with endometrial cancer: 2010 update. Int J Gynecol Cancer 2010;20:1170-87.

64. Rodolakis A, Biliatis I, Morice P, et al. European society of gynecological oncology task force for fertility preservation: clinical recommendations for fertility-sparing management in young endometrial cancer patients. Int J Gynecol Cancer 2015;25:1258-65. 
65. Ramirez PT, Frumovitz M, Bodurka DC, et al. Hormonal therapy for the management of grade 1 endometrial adenocarcinoma: A literature review. Gynecol Oncol 2004;95:133-8.

66. Zhou R, Yang Y, Lu Q, et al. Prognostic factors of oncological and reproductive outcomes in fertility-sparing treatment of complex atypical hyperplasia and lowgrade endometrial cancer using oral progestin in Chinese patients. Gynecol Oncol 2015;139:424-8.

67. Tong XM, Lin XN, Jiang HF, et al. Fertility preserving treatment and pregnancy outcomes in the early stage of endometrial carcinoma. Chin Med J (Engl) 2013;126:2965-71.

68. Kalogera E, Dowdy SC, Bakkum-Gamez JN. Preserving fertility in young patients with endometrial cancer: current perspectives. Int J Womens Health 2014;6:691-701.

69. Wang Q, Guo Q, Gao S, et al. Fertility-conservation combined therapy with hysteroscopic resection and oral progesterone for local early stage endometrial carcinoma in young women. Int J Clin Exp Med 2015;8:13804-10.

70. Wang F, Yu A, Xu H, et al. Fertility preserved hysteroscopic approach for the treatment of stage Ia endometrioid carcinoma. Int J Gynecol Cancer 2017;27:1919-25.

71. Bozdag G, Yarali H, Polat M, et al. ICSI outcome following conservative fertility sparing management of endometrial cancer. Reprod Biomed Online 2009; 18:416-20.

72. Kim MJ, Choe SA, Kim MK, et al. Outcomes of in vitro fertilization cycles following fertility-sparing treatment in stage IA endometrial cancer. Arch Gynecol Obstet 2019;300:975-80.

73. Wang CJ, Chao A, Yang LY, et al. Fertility-preserving treatment in young women with endometrial adenocarcinoma: a long-term cohort study. Int J Gynecol Cancer 2014;24:718-28.

74. Yang YF, Liao YY, Liu XL, et al. Prognostic factors of regression and relapse of complex atypical hyperplasia and welldifferentiated endometrioid carcinoma with conservative treatment. Gynecol Oncol 2015;139:419-23.

75. Inoue O, Hamatani T, Susumu N, et al. Factors affecting pregnancy outcomes in young women treated with fertility-preserving therapy for well-differentiated endometrial cancer or atypical endometrial hyperplasia. Reprod Biol Endocrinol 2016;14:2.

76. Gilabert-Estellés J, Ramón LA, Braza-Boïls A, et al. Plasminogen activator inhibitor-1 (PAI-1) 4 G/5 G polymorphism and endometrial cancer. Influence of PAI-1 polymorphism on tissue PAI-1 antigen and mRNA expression and tumor severity. Thromb Res 2012;130:242-7.

77. Yıldırım ME, Karakuş S, Kurtulgan HK, et al. The association of plasminogen activator inhibitor type 1 (PAI1) level and PAI-1 4G/5G gene polymorphism with the formation and the grade of endometrial cancer. Biochem Genet 2017;55:314-21.

78. Kim MK, Seong SJ, Song T, et al. Comparison of dilatation \& curettage and endometrial aspiration biopsy accuracy in patients treated with high-dose oral progestin plus levonorgestrel intrauterine system for early-stage endometrial cancer. Gynecol Oncol 2013;130:470-3.

79. Ichinose M, Fujimoto A, Osuga Y, et al. The influence of infertility treatment on the prognosis of endometrial cancer and atypical complex endometrial hyperplasia. Int J Gynecol Cancer 2013;23:288-93.

80. Chao AS, Chao A, Wang CJ, et al. Obstetric outcomes of pregnancy after conservative treatment of endometrial cancer: case series and literature review. Taiwan J Obstet Gynecol 2011;50:62-6.

81. Schover LR, van der Kaaij M, van Dorst E, et al. Sexual dysfunction and infertility as late effects of cancer treatment. EJC Suppl 2014;12:41-53.

82. Sadovsky R, Basson R, Krychman M, et al. Cancer and sexual problems. J Sex Med 2010;7:349-73.

83. Rosa VL, Garzon S, Gullo G, et al. Fertility preservation in women affected by gynaecological cancer: the importance of an integrated gynaecological and psychological approach. Ecancermedicalscience 2020;14:1035.

84. Laganà AS, La Rosa VL, Rapisarda AM, et al. Comment on: "Needs and priorities of women with endometrial and cervical cancer". J Psychosom Obstet Gynaecol 2017;38:85-6.
Cite this article as: Topçu HO, Kaya C, Oral E. Fertility issue in early stage endometrial cancer patients. Transl Cancer Res 2020;9(12):7797-7808. doi: 10.21037/tcr-20-2232 